\title{
Reconstructing Past Mass Balance and Climate Conditions from a Cerro Tapado Ice Core (Central Andes, Chile)
}

\author{
Christoph Kull ${ }^{1,2}$ and Patrick Ginot ${ }^{3,4}$ \\ 1PAGES IPO, Sulgeneckstrasse 38, 3007 Bern, Switzerland; kull@pages.unibe.ch \\ ${ }^{2}$ Geographical Institute, University of Bern, 3012 Bern, Switzerland \\ 3IRD, Laboratoire de Glaciologie et de Géophysique de I'Environnement, 38402 Sait-Martin d'Hères, France; ginot@lgge.obs.ujf-grenoble.fr \\ ${ }^{4}$ Department of Chemistry, University of Bern, 3012 Bern and Paul Scherrer Institute (PSI), 5232 Villigen, Switzerland
}

Cerro Tapado $\left(5550 \mathrm{~m}\right.$ asl, $30^{\circ} \mathrm{S} / 69^{\circ} \mathrm{W}$,

Fig. 1) is located in the south central Andes of northern Chile. In 1999, an ice core was drilled and field experiments were carried out in order to understand the recorded ice core history. In this dry area, mass balance is driven by accumulation and sublimation (Fig. 2a). Precipitation on the western side of the Andes at $4000 \mathrm{~m}$ increases from $100 \mathrm{~mm} \mathrm{a}^{-1}$ at $26^{\circ} \mathrm{S}$ to $400 \mathrm{~mm} \mathrm{a}^{-1}$ at $30^{\circ} \mathrm{S}$, and winter precipitation with Pacific moisture is dominant. The summer months are dry. This southward increase in precipitation is also manifested in the presence of isolated glaciers south of $27^{\circ} \mathrm{S}$, where Equilibrium Line Altitudes (ELAs) decrease from $5900 \mathrm{~m}$ at $27^{\circ} \mathrm{S}$ to $5300 \mathrm{~m}$ at $30^{\circ} \mathrm{S}$ (Hastenrath, 1971, Kull et al., 2002, Fig. 2a). CerroTapado is glaciated as low as $4600 \mathrm{~m}$ due to this precipitation increase. However, higher peaks adjacent to CerroTapado, (e.g. Cerro Olivares, $30^{\circ} 17^{\prime} \mathrm{S}, 69^{\circ} 54^{\prime} \mathrm{W}, 6252 \mathrm{~m}$, Fig. 1b), are currently free of glaciers, suggesting that local climatic conditions (e.g., excess precipitation) play an important role (Kull et al., 2002).

\section{Motivation}

Chemical species captured in the ice (e.g., $\mathrm{Cl}^{-}, \mathrm{SO}_{4}{ }^{2-}, \mathrm{Ca}^{2+}, \mathrm{Na}^{+}$) are accumulated by dry and humid deposition and their concentrations are influenced by both changes in their respective sources and climatic conditions. In drier areas, interpretation of chemical concentration records is often difficult due to the strong influence of sublimation. $\delta^{18} \mathrm{O}$, often used for temperature reconstruction, depends also on a range of site-specific climatic conditions, on changes in moisture source properties and on moisture transport history. Thus, ice core records arise as a result of a complicated accumulation history, modified by a myriad of different processes. In the past, climate may have been markedly different,

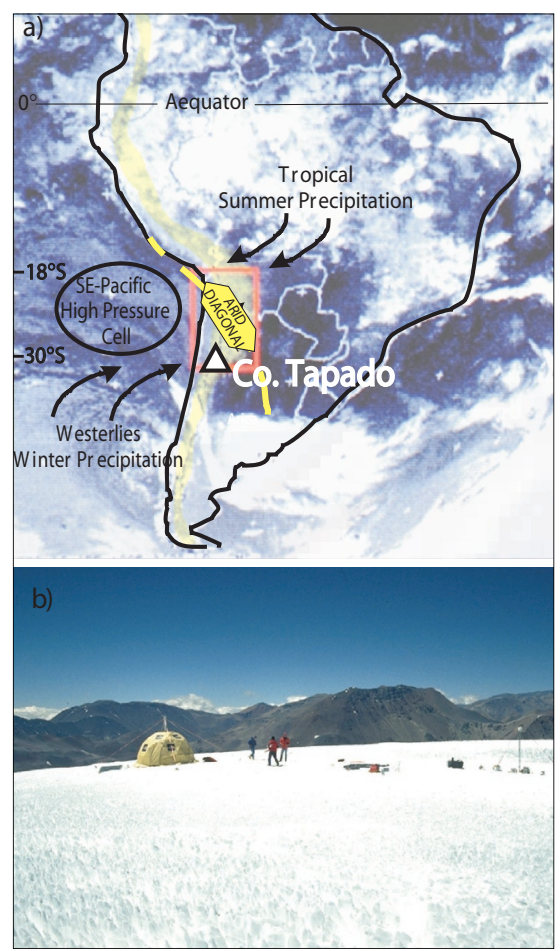

Fig. 1: (a)Location of Cerro Tapado $15550 \mathrm{~m}$ asl./30 $\mathrm{S}$ ) in the North Chilean Andes where the ice core was drilled to bedrock in 1999. (b) View from the ice core drilling and experimental site on Cerro Tapado at $5550 \mathrm{~m}$ to the neighboring higher and ice-free peak of Cerro Olivares (6252m)

including periods of sufficiently low accumulation to be associated with negative mass balance, and therefore a hiatus in the core. Similar gaps in a supposedly "continuous" core can also arise in shear zones. Failure to diagnose such a hiatus in the record leads to an erroneous chronology, an underestimation of past accumulation and an overestimation of the deposition of chemical species-in other words, a completely flawed climatic interpretation. Such effects are

Table 1: Climate reconstruction from the accumulation history in the core using the mass balance model from Kull and Grosjean (2000) and Kull et al. (2002). The paleo reconstruction suggests more humid and colder conditions with a very pronounced precipitation seasonality, in marked contrast to $20^{\text {th }}$ century conditions (Schotterer et al., 2003; Ginot et al., submitted).

\begin{tabular}{|l|c|c|c|c|}
\hline Parameter & $\begin{array}{c}1998 / 1999 \\
\text { measured /modeled }\end{array}$ & $\begin{array}{c}1920 / 1999 \\
\text { modern average }\end{array}$ & $\begin{array}{c}\text { 23-28 m weq. } \\
\text { paleo-conditions }\end{array}$ & $\begin{array}{c}\text { Difference } \\
\text { paleo-modern }\end{array}$ \\
\hline Mean annual Temp. $\left({ }^{\circ} \mathrm{C}\right)$ & -11.5 & $-12.4 \pm 0.2$ & $-15 \pm 1.5$ & $-3( \pm 1.5)$ \\
\hline Total accumulation $(\mathrm{mm} / \mathrm{y})$ & 750 & $540 \pm 45$ & $830 \pm 50$ & $+290 \pm 150$ \\
\hline Winter accumulation $(\mathrm{mm})$ & 500 & $310 \pm 45$ & $780 \pm 50$ & $+470 \pm 100$ \\
\hline Summer accumulation $(\mathrm{mm})$ & 250 & $230 \pm 45$ & $50 \pm 50$ & $-180 \pm 100$ \\
\hline Sublimation $(\mathrm{mm} / \mathrm{y})$ & 490 & 240 & 620 & +380 \\
\hline Net accumulation $(\mathrm{mm} / \mathrm{y})$ & 260 & 300 & 210 & -80 \\
\hline
\end{tabular}

often difficult to detect but may play an important role when interpreting "continuous" ice core records back to the Last Glacial Maximum.

\section{Methodology}

A modeling approach was used to obtain a more rigorous ice core based climatic reconstruction of the site- and archive-specific accumulation history. Field experiments were carried out (Fig. 2, Kull et al., al., 2001, Ginot et al., submitted, Schotterer et al., 2003) in order to quantitatively estimate the climatic controls on local mass balance (sublimation, melt, accumulation) and to assess the post-depositional effects on environmental tracers stored in the firn (Fig. 2b). These experiments confirmed that post-depositional processes, mainly sublimation, have a substantial influence on the ice and snow surface. The loss of water by sublimation (around $2 \mathrm{~mm}$ per day) during fair weather results in an enrichment of conservative chemical species and a reduction in accumulation. This process may even lead to a negative mass balance in particularly dry years. In a second step, the mass balance (sublimation, accumulation, melt) at the coring site and the related changes in the concentration of conservative chemical species was modeled (Ginot et al., 2001, Kull et al. 2002). These models were based on local climatic data and field measurements of sublimation and 2002, Ginot et al., 2001, Stichler et 


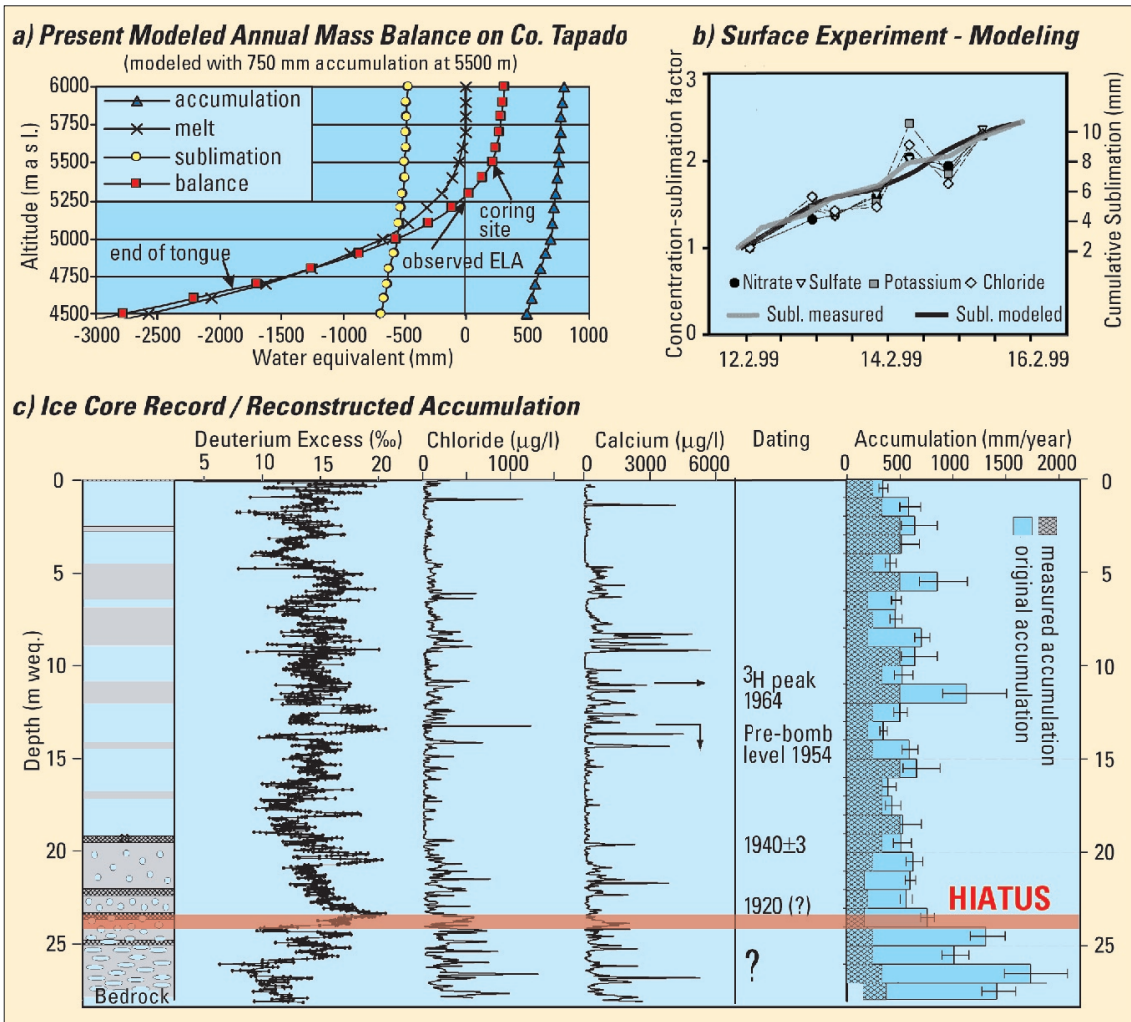

Fig. 2: (a)Balance-elevation distribution of Cerro Tapado modeled with local climatic data. A local surplus of $250 \mathrm{~mm}$ is necessary to explain the recent isolated glaciation in the region. This value is supported by the ice core data. Ablation is mainly driven by sublimation. (b)Results of the surface experiment showing the measured and modeled daily sublimation amounts, as well as the related concentrations of chemical species. There is a clear linear relationship between the measured concentrations of chemical species and measured sublimation. This relationship can then be applied to model past sublimation from measured chemical species concentrations in ice cores. A mass balance model (Kull and Grosjean, 2000; Kull et al., 2002) and a model for the concentration of chemical species (Ginot et al., 2001) can be used to calculate specific mass balance and climate conditions from the ice core record (Table 1). (c)/ce core record from Cerro Tapado: The ice core stratigraphy and ${ }^{2} \mathrm{H}$ excess both show clear differences between the core sections below and above $23 \mathrm{~m}$ weq. The variation in the concentration of the chemical species, which is directly linked to sublimation changes, results from climate variability (Schotterer et al., 2003; Ginot et al., submitted). Reconstruction of the original ice accumulation as corrected for sublimation losses.

enrichment of some chemical species (Fig. 2b).

\section{Results}

Mass loss and modification of chemical constituents have significant consequences for the interpretation of the paleo-record from the Cerro Tapado ice core. Bedrock was reached at $36 \mathrm{~m}$ (28m water equivalent (weq) (Fig. 2c). Dating was performed by a combination of annual layer counting (assuming that regular wet and dry periods lead to low and high concentrations of chemical constituents), ${ }^{210} \mathrm{~Pb}$, tritium fallout from nuclear weapons tests, and a firn densification model. Dating showed that the upper half of the accumulated ice is younger than 50 years, as indicated by the pre-bomb tritium level of 1952 , and that more than $80 \%$ of the ice has accumulated during the $20^{\text {th }}$ century (Schotterer et al., 2003, Figure 2c). However, the lowermost ice must have been formed under very different climatic conditions in the more distant past. Below 23m weq, a distinct change is apparent in both the ice core stratigraphy and the concentration profiles of isotopes and chemical constituents compared to the upper part of the ice core (Fig. 2c). The reconstructed history in this part of the core shows that accumulation must have been driven by massive sublimation losses during the buildup of the glacier (Fig. 2c). The climatic interpretation, consistent with both the ice core data and the climate-massbalance model (Kull and Grosjean, 2000, Kull et al., 2002), points to lower temperatures $\left(-3^{\circ} \pm 1.5^{\circ} \mathrm{C}\right)$, higher annual precipitation (290 \pm $150 \mathrm{~mm}$ ) and increased seasonality in the moisture supply (Table
1). High precipitation in the humid winter season is responsible for the necessary accumulation, while the extended dry season relates to the pronounced sublimation. Today the timing of this climatic regime remains unclear. However, the presence of a time and accumulation hiatus of unknown age and duration is clearly indicated and raises concerns and speculations.

\section{Paleoclimatic Implications - Outlook}

When did the buildup of the glacier start? In 1890, Brackebusch reported that the Agua Negra glacier, located a few kilometers east in Argentina $\left(30^{\circ} 15^{\prime} \mathrm{S}, 69^{\circ} 50^{\prime} \mathrm{W}\right)$, showed a markedly greater extension than today. It is therefore probable that the nearby CerroTapado glacier also existed during this time. On the other hand, given the dry climate of the mid-Holocene (Maldonado and Villagran, 2002) one would not expect any glacier growth in the region.

Since the formation of the basal ice body, climate conditions have not caused a complete ablation. A significantly high concentration peak of the conservative chemical species and accumulation of mineral particles would be expected to identify a hiatus by partial ablation of the glacier due to sublimation, as recorded from the Agua Negra glacier (Milana and Maturano, 1999). This is not observed and implies that the hiatus must be explained by ice flow over the basal frozen ice body.

Today, a negative annual mass balance results if the annual netaccumulation does not exceed $500 \mathrm{~mm}$ (Fig. 2a, Table 1). Assuming extremely dry climatic conditions, as observed in the ice-free "South American Arid Diagonal" (annual precipitation around $280 \mathrm{~mm}$, Fig. 1), a negative annual mass balance of $-500 \mathrm{~mm}$ is calculated after Kull and Grosjean (2000), requiring 50 extremely dry years for a complete ablation of the actual ice mass. Therefore, extremely dry periods could not have persisted over longer periods since the glacier buildup. A late-Holocene $(<2600$ $\mathrm{BP})$ glacier advance is recorded in 


\section{Science Highlights}

the area around $30^{\circ} \mathrm{S}$. (Grosjean et al., 1998). These morrains also exist in the surroundings of Cerro Tapado. Ongoing research aims to test whether the glacier model can produce the observed late Holocene glacier extent using the ice core derived climate conditions, and therefore link ice core and modeling results with geomorphological evidence of past glacier advances.
REFERENCES

Brackebusch, L., 1892: Die Kordillerenpässe zwischen der argentinischen Republik und Chile. Zeitschr. Ges. Erdk, t. 27

Ginot, P., Kull, C., Schwikowski, M., Schotterer, U. \& Gäggeler, H.W., 2001: Effects of postdepositional processes on snow composition of a subtropical glacier (Cerro Tapado, Chilean Andes), J. Geophys. Res., 106: D23, 32, 375 (2000JD000071).

Kull, C., Grosjean, M. \& Veit, H., 2002: Modeling Modern and Late Pleistocene glacio-climatological conditions in the North Chilean Andes (29. S - 30 S), Climatic Change, 52, 359-381.

Maldonado, A. \& Villagran, C., 2002: Paleoenvironmental changes in the semiarid coast of Chile $\left(32^{\circ} \mathrm{S}\right)$ during the last $6200 \mathrm{cal}$ years inferred from a swamp-forest pollen record. Quaternary Research, 58, 130-138.

Schotterer, U., Grosjean, M., Stichler, W., Ginot, P., Kull, C., Bonnaveira, H., Francou, B., Gäggeler, H.W. Gallaire, R., Hoffmann, G., Pouyaud, B., Ramirez, E., Schwikowski, M. \& Taupin, J.D., 2003: Glaciers and climate in the Andes between the Equator and $30^{\circ} \mathrm{S}$ : What is recorded under extreme environmental conditions? Climatic Change, 59:1-2, 157-175.

\section{The Southern Ocean as the Flywheel of the Oceanic Conveyor Belt Circulation}

GREGOR KNORR $^{1,2}$ AND GERRIT LOHMANN ${ }^{1,2}$

IInstitute for Meteorology, University of Hamburg, Bundesstrasse 55, 20146 Hamburg, Germany; gregor.knorr@dkrz.de

${ }^{2}$ DFG Research Center Ocean Margins and Dept. of Geosciences, University of Bremen, Bremen 28334, Germany; gerrit@palmod.uni-bremen.de

The last ice age came to an end between 20 and $10 \mathrm{ka}$ BP. This time span was punctuated by a series of abrupt climate sequences (Fig.1a). In particular, the rapid transition in the North Atlantic from the cold Heinrich 1 to the Bølling/Allerød (B/ A) warm-phase and its cold reversal counterpart in Antarctica (ACR) have attracted much attention. During deglaciation, the North Atlantic was exposed to a large meltwater discharge from the melting Laurentide and Fennoscandian ice sheets. This continuous meltwater release on the order of about $0.1 \mathrm{~Sv}$ (Marshall and Clarke, 1999) posed a constant threat to the "Achilles Heel" of the oceanic conveyer belt circulation (Broecker, 1991), located in the North Atlantic (schematic picture in Fig. 2a, b). Paleodata (Duplessy et al., 1988; Sarnthein et al., 1994) and modeling work (e.g., Ganopolski and Rahmstorf, 2001; Prange et al., 2002) indicate a weaker glacial thermohaline circulation (THC) compared with the interglacial circulation. Based on evidence of a weak glacial conveyor belt, it is natural to ask about the "flywheel" of the ocean circulation, which might have initiated the transition to a strong interglacial ocean circulation. This "flywheel" is not necessarily confined to the North Atlantic realm, where the "Achilles Heel" is located. Our recent modeling results (Knorr and Lohmann, 2003) using an Oceanic General

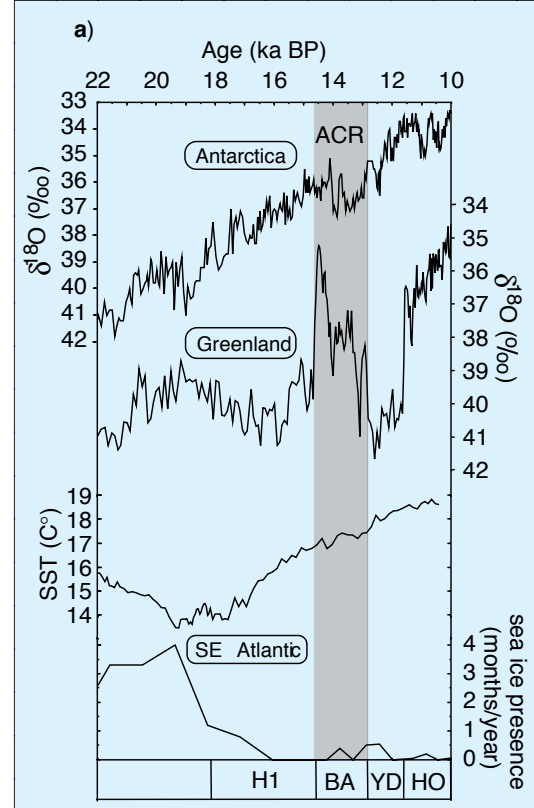

b)
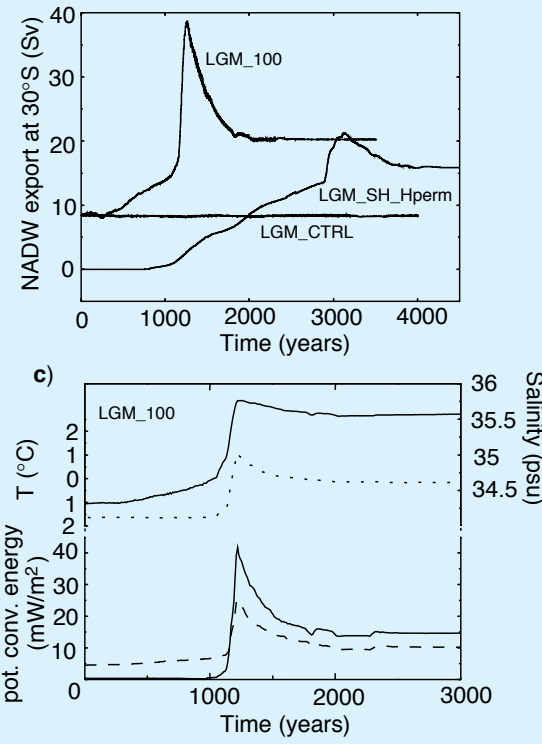

Fig. 1: Deglacial climate records and modeling results for the Bølling/Allerød transition induced by Southern Hemisphere warming. (a) High-resolution climate records from 22 to $10 \mathrm{ka}$ BP based on polar ice cores from Antarctica (BYRD) and Greenland (GISP2) during the last deglaciation (Blunier and Brook, 2001), including a sequence of abrupt climate changes (boundaries of climate intervals, defined as per the GISP2 record: H1, Heinrich 1; BA, Bølling-Allerød; YD, Younger Dryas; HO, Holocene). The temperature evolution of alkenone-based sea-surface temperatures (SST) in the south east Atlantic (Sachs et al., 2001), showing that deglacial warming at $41^{\circ} \mathrm{S}, 7.5^{\circ} \mathrm{E} \mathrm{com}$ menced between 17.5 to $19 \mathrm{ka} \mathrm{BP}$, similar to the Antarctic warming trend. At the same time, sea ice in the Southern Ocean retreated to present day limits (Shemesh et al., 2002). (b)Temporal changes in NADW export at $30^{\circ}$ S. In LGM_100 and LGM_SH_Hperm, glacial conditions in the Southern Ocean (south of $30^{\circ} \mathrm{S}$ ) are gradually replaced by interglacial conditions over 1500 years. LGM SH Hperm is started from the THC "off-mode" and superposed by a permanent freshwater flux of $0.15 \mathrm{~Sv}\left(1 \mathrm{~Sv}=10^{6} \mathrm{~m}^{3} \mathrm{~s}^{-1}\right)$ to the North Atlantic. LGM_CTRL represents the glacial control run. (c) LGM_100 time series of sea surface temperature $\left({ }^{\circ} \mathrm{C}\right.$, dotted curve), salinity (psu, solid curve) and potential energy loss by convection $\left(\mathrm{mW} / \mathrm{m}^{2}\right)$ in the North Atlantic averaged between $55^{\circ} \mathrm{N}$ and $65^{\circ} \mathrm{N}$ (solid curve) and between $40^{\circ} \mathrm{N}$ and $55^{\circ} \mathrm{N}$ (dashed curve).

Circulation Model (OGCM) (MaierReimer et al., 1993; Lohmann et al., 2003) suggest that Southern Ocean warming and the accompanying sea ice retreat induced a non-linear transition to a strong Atlantic overturning circulation (Fig. 1b).
This is consistent with ice core and ocean-sediment records, showing that a progressive warming in the Southern Hemisphere preceded Greenland warming by more than 1000 years (Sowers and Bender, 1995), a time lag that was even lon- 